\title{
Ketamine destabilizes growth of dendritic spines in developing hippocampal neurons in vitro via a Rho-dependent mechanism
}

\author{
SUFANG JIANG $^{1 *}$, ZIMIAO HAO $^{1,2^{*}}$, XUZE LI $^{1}$, LIJUN BO $^{1}$, RUI ZHANG ${ }^{1}$, YING WANG $^{1}$, \\ XIAOFENG DUAN $^{1}$, RONGTIAN KANG ${ }^{1}$ and LINING HUANG ${ }^{1}$ \\ ${ }^{1}$ Department of Anesthesiology, The Second Hospital of Hebei Medical University, Shijiazhuang, Hebei 050000; \\ ${ }^{2}$ Department of Anesthesiology, Affiliated Hospital of Hebei University, Baoding, Hebei 071000, P.R. China
}

Received March 23, 2018; Accepted September 10, 2018

DOI: $10.3892 / \mathrm{mmr} .2018 .9531$

\begin{abstract}
The safety of anesthetics on the developing brain has caused concern. Ketamine, an N-methyl-D-aspartate receptor antagonist, is widely used as a general pediatric anesthetic. Recent studies suggested that ketamine alters the plasticity of dendritic spines in the developing brain and may be an important contributing factor to learning and cognitive impairment. However, the underlying molecular mechanism remains poorly understood. Therefore, the aim of the present study was to investigate the effect of ketamine on the plasticity of dendritic spines in cultured hippocampal neurons and the potential underlying mechanisms. After 5 days in vitro, rat hippocampal neurons were exposed to different concentrations $(100,300$ and $500 \mu \mathrm{M})$ of ketamine for $6 \mathrm{~h}$. Ketamine decreased the number and length of dendritic spines in a dose-dependent manner. Ketamine at a concentration of $300 \mu \mathrm{M}$ caused an upregulation of transforming protein RhoA (RhoA) and Rho-associated kinase (ROCK) protein. These effects were inhibited by the ROCK inhibitor Y27632. These results suggested that ketamine induces loss and shortening of dendritic spines in hippocampal neurons via activation of the RhoA/ROCK signaling pathway.
\end{abstract}

\section{Introduction}

There is growing concern regarding the safety of anesthetics on the developing brain. Previous studies demonstrated that early post-natal anesthesia has neurotoxic effects in rodents and other animals $(1,2)$. Anesthesia of children aged $<3$ years old in surgery increases the risk of learning and memory

Correspondence to: Professor Lining Huang, Department of Anesthesiology, The Second Hospital of Hebei Medical University, 215 West Heping Road, Shijiazhuang, Hebei 050000, P.R. China E-mail: 15803213730@163.com

${ }^{*}$ Contributed equally

Key words: ketamine, transforming protein RhoA, Rho-associated kinase, dendritic spines, hippocampus impairment (3). The use of ketamine is well established in pediatric anesthesia and it is used for induction and maintenance of anesthesia $(4,5)$. An increasing number of studies demonstrated that ketamine causes anesthetic neurotoxicity. Previous studies in rodent and primate models have confirmed that ketamine anesthesia during critical periods of brain development may result in functional deficits $(6,7)$.

Dendritic spines are the anatomical locus of the majority of excitatory synapses in the central nervous system (8). Dendritic spines arise as small protrusions from the dendritic shaft of various types of neuron and receive inputs from excitatory axons (9). Alterations in the morphology and number of dendritic spines are associated with alterations in synaptic efficacy, learning and memory, and other cognitive processes $(10,11)$. Previous studies demonstrated that ketamine causes learning and behavioral impairment, primarily due to a reduction in synaptic structural plasticity $(12,13)$. The present study investigated the underlying mechanism by which ketamine affects synaptogenesis in early developing hippocampal neurons of rats.

Transforming protein RhoA (RhoA) guanosine triphosphate hydrolases (GTPases) and their downstream signals are critical in the association of neuronal activity with various forms of neuronal plasticity $(14,15)$. Volatile anesthetics lead to neuronal apoptosis and length-shortening of dendritic protrusions by activating RhoA in developing neurons $(16,17)$. In the present study, it was hypothesized that ketamine may alter the number and length of dendritic spines in early developing hippocampal neurons via activation of the RhoA/Rho-associated kinase (ROCK) signaling pathway.

\section{Materials and methods}

Ethics statement. The Institutional Animal Care and Use Committee of Hebei Medical University (Shijiazhuang, China) specifically approved the present study. All of the animals were handled according to this approved protocol.

Animals. A total of eight $24 \mathrm{~h}$ postnatal Sprague-Dawley rats, weighing 4.5 6.5 g, were provided by the Laboratory Animal Center of Hebei Medical University (Hebei, China). Animals were kept in a 40-60\% humidity and temperature-controlled 
$\left(22-23^{\circ} \mathrm{C}\right)$ room under a 12 -h light/dark cycle (light on at 7:00 AM); standard rat chow and water were available ad libitum. Housing was provided with appropriate tactile, olfactory, visual, and auditory stimuli.

Primary neuron cultures. The rats were quickly decapitated and their brains were aseptically dissected and immersed in ice-cold dissecting solution, consisting of Hanks' Balanced Salt Solution. Bilateral hippocampal tissues were exposed and removed from the 24-h post-natal Sprague-Dawley rats and subsequently disinfected with $75 \%$ alcohol. Subsequent to the removal of blood vessels and meninges, the hippocampal tissues were cut into pieces that were as small as possible. These pieces were centrifuged for $100 \mathrm{x} \mathrm{g}$ and $5 \mathrm{~min}$ at room temperature. Subsequent to discarding the supernatant, Accutase ${ }^{\circledR}$ (Thermo Fisher Scientific, Inc., Waltham, MA, USA) was added to the hippocampal tissues at a volume of $3: 1$. The samples were placed in an incubator for 10-20 min for digestion. The tissues were vortexed numerous times during the digestion and Dulbecco's modified Eagle's medium (DMEM) with $10 \%$ fetal bovine serum (FBS; Gibco; Thermo Fisher Scientific, Inc.) was added to terminate the digestion process. The tissues were thoroughly dispersed by pipetting and subsequently filtered through a 200-mesh copper filter. The filtered cells were collected and centrifuged at $100 \mathrm{x}$ g for $5 \mathrm{~min}$ at room temperature. Subsequently, the supernatant was discarded, DMEM with $10 \%$ FBS was added, and the cells were dispersed in order to obtain a cell suspension. Cells $\left(1 \times 10^{6}\right.$ cells/well $)$ were plated in 6-well plates for $24 \mathrm{~h}$. The culture medium was replaced with neurobasal medium (Invitrogen; Thermo Fisher Scientific, Inc.) containing 1\% N2 and 2\% B27. Half of the culture medium was changed every two days. Cells were cultured at $37^{\circ} \mathrm{C}$ in a $5 \% \mathrm{CO}_{2}$ incubator.

Immunofluorescence procedures and purity identification. Cells were fixed with $4 \%$ formaldehyde for at room temperature for $30 \mathrm{~min}$. The cells were then incubated with $5 \%$ goat serum (Novus Biologicals, LLC, Littleton, CO, USA) at room temperature for $10 \mathrm{~min}$ and immunostained with microtubule-associated protein 2 (MAP2; cat. no. 554002, 1:50; BD Biosciences, Franklin Lakes, NJ, USA) antibody at $4^{\circ} \mathrm{C}$ overnight, followed by incubation with goat anti-mouse immunoglobulin G secondary antibody (cat. no. NBP2-44080, 1:50, Novus Biologicals, Colorado, USA) at room temperature for $45 \mathrm{~min}$. The nuclei were stained with DAPI (Enzo Life Sciences, Inc., Farmingdale, NY, USA) at room temperature for $30 \mathrm{~min}$. Images of each slide were captured using a Zeiss Axiovert Upright Fluorescence microscope (magnification, x40 and x200; Zeiss AG, Oberkochen, Germany) and fluorescent intensity was quantified using Image Pro Plus version 6.0 (Media Cybernetics, Inc., Rockville, MD, USA). The purity of neurons (\%) was calculated as follows: (Number of MAP2 positive cells/number of DAPI positive cells) x100.

Celltreatmentwithreagents. Afterculturing for 5 days, cells were exposed to control (PBS), ketamine (100, 300 and $500 \mu \mathrm{M})$, $10 \mu \mathrm{M}$ Y27632 (ScienCell Research Laboratories, Inc., San Diego, CA, USA) or ketamine and Y27632 at 5 days in vitro (DIV). After treatment for $6 \mathrm{~h}$, cells were washed with PBS and subsequently incubated for $5 \mathrm{~min}$ at $37^{\circ} \mathrm{C}$ with Vybrant ${ }^{\mathrm{TM}}$ CM-Dil Cell-Labeling solution (cat. no. V22888; Thermo Fisher Scientific, Inc.). Cells were fixed with $4 \%$ formaldehyde at room temperature for $30 \mathrm{~min}$. Following rinsing, slides were mounted for imaging. Fluorescence images were captured using confocal microscopy (magnification, x400 and x1,000; Nikon Corporation, Tokyo, Japan). Vybrant ${ }^{\mathrm{TM}}$ CM-Dil Cell-Labeling solution-stained fluorescence images appeared in red or, following transformation using Image-J version 2.0 software (National Institutes of Health, Bethesda, MD, USA), in black and white.

Analysis of spine density. All dendrite and spine tracing was performed by an investigator, who was blind to the experimental treatment group. Fluorescence images were captured using confocal microscopy (magnification, x400 and x1,000; Nikon Corporation). Analysis of spine plasticity was performed using Image J software, as previously described (17). Dendrite segments located distal to the first branch point from the cell soma and including the most distally-located dendritic segments (2-5 per neuron) were randomly selected for analysis. For each examined neuron, one $100-\mu \mathrm{m}$ long segment from a second- or third-order dendrite (protruding from its parent apical dendrite) was selected for spine density quantification (18). For spine length quantification, length was determined as the distance between the base and top of the spine head.

Western blot analysis. Cells were harvested $6 \mathrm{~h}$ after treatment with reagents and lysed in a buffer containing $50 \mathrm{mM}$ Tris- $\mathrm{HCl}$ (pH 7.5), $150 \mathrm{mM} \mathrm{NaCl}, 2$ mM EDTA, $1 \%$ Triton, $1 \mathrm{mM}$ PMSF and Protease Inhibitor Cocktail (1:50; Beyotime Institute of Biotechnology, Shanghai, China) for $20 \mathrm{~min}$ on ice. Lysates were separated by centrifugation at 15,000 x g at $4^{\circ} \mathrm{C}$ for $20 \mathrm{~min}$. Supernatants were collected and the protein concentrations were determined by a Bradford assay. Proteins $(150 \mu \mathrm{g})$ were subjected to electrophoresis on $12 \%$ SDS-PAGE and were subsequently transferred to polyvinylidene difluoride membranes. Membranes were blocked in Tris-buffered saline (pH 7.4) with 5\% non-fat dry milk at room temperature for $1 \mathrm{~h}$, and probed with primary antibodies at $4^{\circ} \mathrm{C}$ overnight. The following antibodies were used: RhoA (cat.no.ab187027; 1:500), ROCK (cat. no. ab71598; 1:500) and $\beta$-actin (cat. no. ab8226; 1:500; Abcam, Cambridge, UK). Then, the cells were washed with TBST three times for $10 \mathrm{~min}$ each and then incubated with peroxidase-labeled affinity purified antibody to Rabbit IgG (cat. no. ZDR-5306; OriGene Technologies, Inc., Beijing, China) or peroxidase-labeled affinity purified antibody to Mouse IgG (cat. no. ZDR-5307; OriGene Technologies, Inc., Beijing, China) at room temperature for $2 \mathrm{~h}$. Blots were detected using an enhanced chemiluminescence plus system (MiniChemi 610 Plus; 304002L; Beijing Sage Creation Science Co., Ltd., Beijing, China). Quantification (sageCapture3.0, Service For Life Science) of the western blots was conducted using sageCapture version 3.0 (Beijing Sage Creation Science Co., Ltd.,).

Statistical analysis. All experiments were repeated three times. Statistical analysis was performed using GraphPad Prism version 5.0 software (GraphPad Software, Inc., La Jolla, CA, USA). All data are presented as the mean \pm standard error of 
A

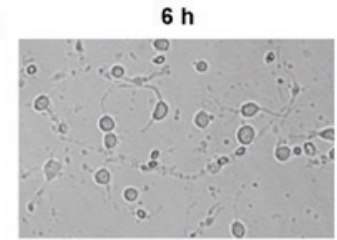

B a

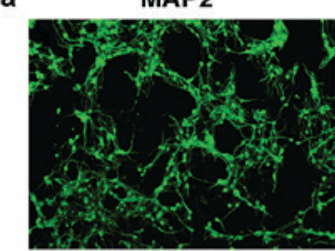

b

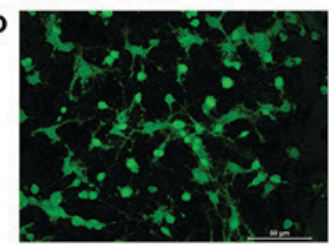

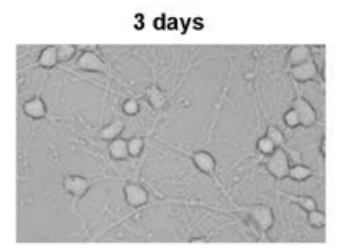

DAPI
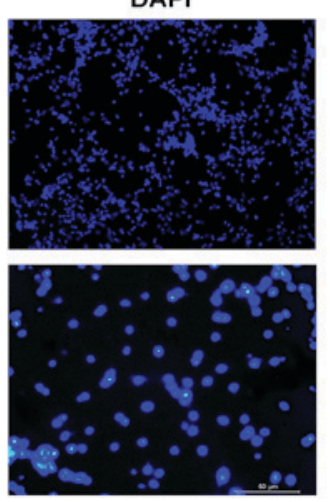

7 days

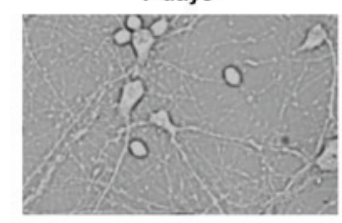

Merged
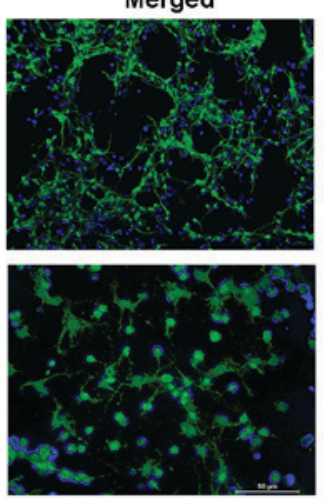

Figure 1. Morphology and purity of hippocampal neurons cultured in vitro. (A) Morphology of hippocampal neurons at various time points. (B) Immunofluorescence in 7 DIV hippocampal neurons. Neurons were stained with MAP2 and DAPI, and images are merged. Neurons were observed using an inversion fluorescence microscope and representative images at (Ba) magnification x40 and (Bb) magnification x200 are presented. MAP2, microtubule-associated protein 2.

the mean. The density and mean length of dendritic spines were analyzed with one-way analysis of variance. Post hoc individual means comparisons were performed using the LSD-t-test. $\mathrm{P}<0.05$ was considered to indicate a statistically significant difference.

\section{Results}

Morphology and purity of hippocampalneurons. Cells cultured in vitro adhered to the surface and demonstrated a spindle shape. At $3 \mathrm{DIV}$, the neurons were typically spindle-shaped and developed into a sparse network that primarily formed an in vitro neural network. After $7 \mathrm{DIV}$, the network and effective synaptic connections formed by axons and dendrites were enhanced (Fig. 1A). The purity of hippocampal neurons was subsequently determined. The microtubule-associated protein MAP2 preferentially localizes to dendrites; however, not to axons, and is a useful marker for dendrites in cell culture (19). In total, $91 \%$ of the cells were identified as neurons, demonstrated by MAP2 staining (Fig. 1B).

Ketamine decreases the density and length of dendritic spines in a dose-dependent manner. The effects of ketamine on the length and density of dendritic spines were assessed. At 5 DIV, hippocampal neurons were treated with different concentrations $(100,300$ and $500 \mu \mathrm{M})$ of ketamine for $6 \mathrm{~h}$. Representative images of dendritic spines in vehicle (unexposed) or ketamine-exposed neurons are presented in Fig. 2A. Ketamine caused a dose-dependent decrease in the number and length of dendritic spines (Fig. 2B and C). There was no significant difference between the $100 \mu \mathrm{M}$ ketamine-exposure group (number, 36.47 \pm 8.23 ; length, $45.87 \pm 5.01 \mu \mathrm{m}$ ) and control cells (number, 40.88 \pm 7.61 ; length, $47.69 \pm 4.28 \mu \mathrm{m}$ ). Concentrations of 300 and $500 \mu \mathrm{M}$ ketamine significantly decreased the density and length of dendritic spines (number, 20.31 \pm 5.87 , length, 30.71 $\pm 5.52 \mu \mathrm{m}$; and number, $7.23 \pm 2.01$; length, $10.68 \pm 3.53 \mu \mathrm{m}$, respectively; $\mathrm{P}<0.05)$ compared with the control. Furthermore, $500 \mu \mathrm{M}$ ketamine significantly decreased the number and length of dendritic spines compared with $300 \mu \mathrm{M}$ ketamine $(\mathrm{P}<0.05)$. These results suggested that ketamine decreases the density and length of dendritic spines in a dose-dependent manner.

ROCK inhibitor attenuates ketamine-induced dendritic spine loss and length-shortening. During early development, activation of the RhoA-ROCK pathway is involved in immature dendritic protrusions on hippocampal neurons (20). Therefore, the role of the RhoA-ROCK pathway in ketamine-induced dendritic spine loss and length-shortening was investigated in the present study. Neurons treated with ketamine for 5 DIV were incubated in the presence of $10 \mu \mathrm{M}$ Y27632, a specific inhibitor of ROCK (21). Ketamine upregulated RhoA and ROCK protein expression levels, whereas, Y27632 attenuated the expression of ROCK (Fig. 3A). The number and length of dendritic spines differed among the four groups. Neurons treated with ketamine had fewer $(15.57 \pm 6.23)$ and shorter length $(20.01 \pm 3.87 \mu \mathrm{m})$ dendritic spines compared with the control neurons (number, 40.65 \pm 5.78 ; length, $50.78 \pm 6.38 \mu \mathrm{m}$ ). Treatment with Y27632 in the presence of ketamine significantly prevented dendritic spine loss and length-shortening (number, 28.67 \pm 5.83 ; length, $34.89 \pm 4.87 \mu \mathrm{m}$ ). Compared with the control group, the neurons treated with Y27632 demonstrated no significant difference in number or length of dendritic spines (Fig. 3B-D).

\section{Discussion}

The results of the present study suggested that early exposure of rat hippocampal neurons to ketamine substantially decreases 
A
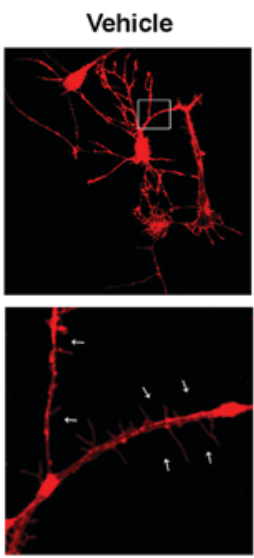

B

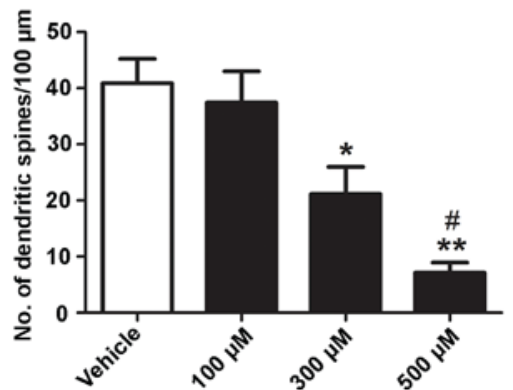

$100 \mu \mathrm{M}$
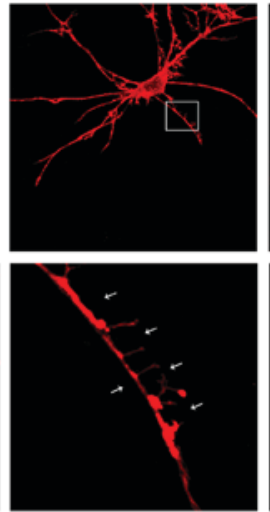
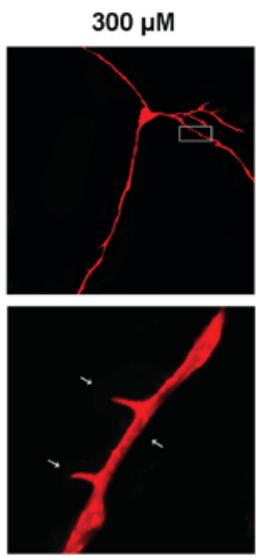

C

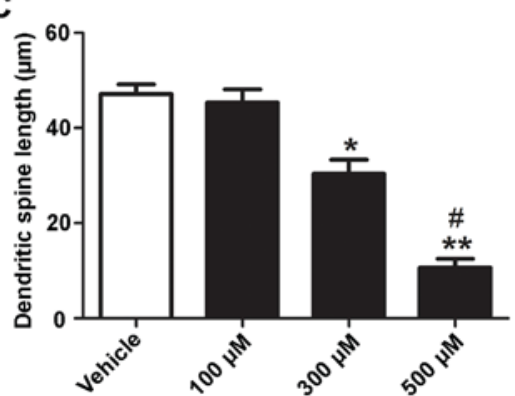

Figure 2. Ketamine reduces the density and alters the mean length of dendritic spines. At 5 days in vitro, rat hippocampal neurons were exposed to different concentrations $(100,300$ and $500 \mu \mathrm{M})$ of ketamine for $6 \mathrm{~h}$. (A) Representative images demonstrating the dendritic arbor development of a control neuron and of a neuron treated with ketamine. Neurons were exposed to different concentrations of ketamine. White arrows indicate dendritic spines. (B) Number of dendritic spines per $100 \mu \mathrm{m}$. (C) Dendritic spine length. $\mathrm{n}=10$. Magnification, $\mathrm{x} 400$ and $\mathrm{x} 1,000$. $^{*} \mathrm{P}<0.05,{ }^{* *} \mathrm{P}<0.01$ vs. vehicle; ${ }^{*} \mathrm{P}<0.05$ vs. $300 \mu \mathrm{M}$ ketamine.

the density and length of dendritic spines. The selective ROCK inhibitor Y27632 partly attenuates the effects induced by ketamine, suggesting that the RhoA/ROCK signaling pathway is involved in ketamine-induced neurotoxicity in the developing brain.

A previous study demonstrated that in rats the blood concentration of ketamine was $\sim 20 \mu \mathrm{M}$ and the brain plasma ratio of ketamine was 6.5:1 (22), thus, 100-300 $\mu \mathrm{M}$ ketamine is clinically relevant (blood concentration of ketamine was $\sim 20 \mu \mathrm{M}$ and the brain plasma ratio of ketamine was $6.5: 1$, $(20 \times 6.5=130 \mu \mathrm{M})$. A high concentration of ketamine has been widely used in a large number of in vitro experiments to investigate its mechanisms of neurotoxicity (23-25). In the present study, concentrations of ketamine ranging between 100 and $500 \mu \mathrm{M}$ were selected.

Previous studies demonstrated that the impact of ketamine on dendritic spines is dependent on developmental age. Exposure to ketamine decreases the density of synapses or spines in the hippocampus of neonatal rodents at 5-13 days post-natal (12). Treatment of mouse hippocampal neurons with ketamine for $5 \mathrm{~h}$ at 15 and 30 days post-natal caused an age-dependent significant increase in dendritic spine density (26). These previous studies identified a mechanism for the modulation of synaptogenesis via modulation of the excitation/inhibition balance by ketamine. In the present study, rats were sacrificed $24 \mathrm{~h}$ post-natal. At $5 \mathrm{DIV}$, neurons treated with ketamine for $6 \mathrm{~h}$ exhibited a decrease in dendritic spine density and mean length in a dose-dependent manner, which is consistent with the results of a previous study (12). This suggested that ketamine impairs the morphology of dendritic spines during early post-natal development.

The small GTPase Rho is critical in regulating actin remodeling in dendritic spines (27). RhoA regulates maturation of adhesions and the postsynaptic density of dendritic spines (28). Activation of RhoA/ROCK signaling leads to dendritic spine shrinkage and synapse loss (29). Conversely, blocking activation of ROCK induces novel, long spines and protrusive motility (30). In the present study, ketamine induced upregulation of RhoA and ROCK protein expression levels. Furthermore, Y27632, an inhibitor of ROCK, attenuated dendritic spine loss and length-shortening, suggesting that the mechanism of ketamine anesthetic neurotoxicity is partly via activation of the RhoA/ROCK signaling pathway. A previous study demonstrated that the anesthetic agent isoflurane destabilizes spine actin, which results in alterations to dendritic spine morphology and number (31). Zimering et al (17) additionally observed that sevoflurane causes actin depolymerization, leading to reversible length-shortening of dendritic protrusions through a mechanism involving activation of RhoA/ROCK signaling. Ketamine is commonly used as an intravenous general anesthetic for pediatric patients. These results are consistent with the possibility that activation of the RhoA/ROCK signaling pathway is one of the mechanisms of the neurotoxicity of ketamine when used as an anesthetic.

The ROCK inhibitor Y27632 has been demonstrated to strongly stimulate neurite outgrowth (32). A previous study identified that treatment of 13 DIV hippocampal neurons with $100 \mu \mathrm{M}$ Y 27632 for 3 days increased the density and length of dendritic spines of cultured neurons (33). Swanger et al (21) 
A

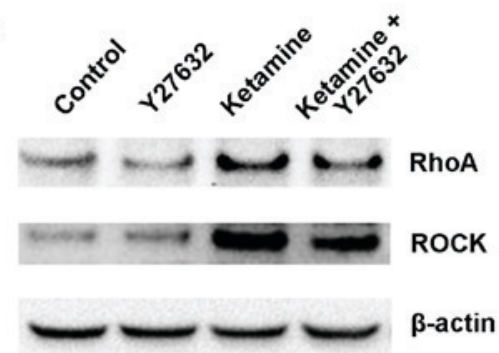

$\mathrm{B}$ a

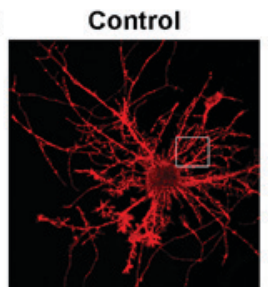

b

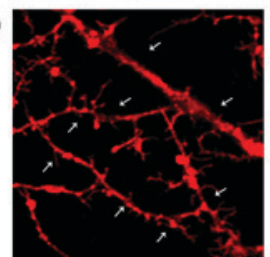

C

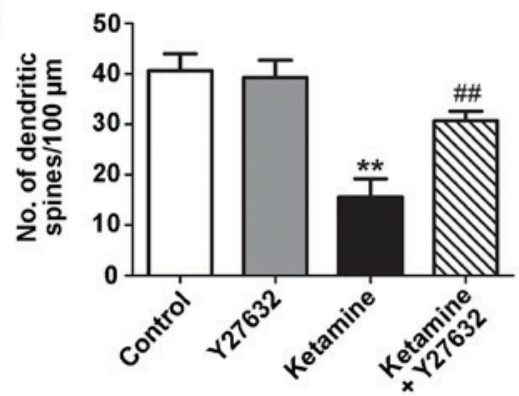

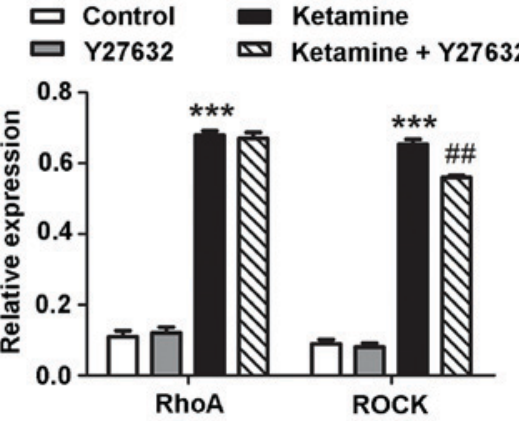

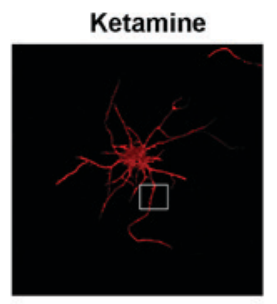

Ketamine + Y27632
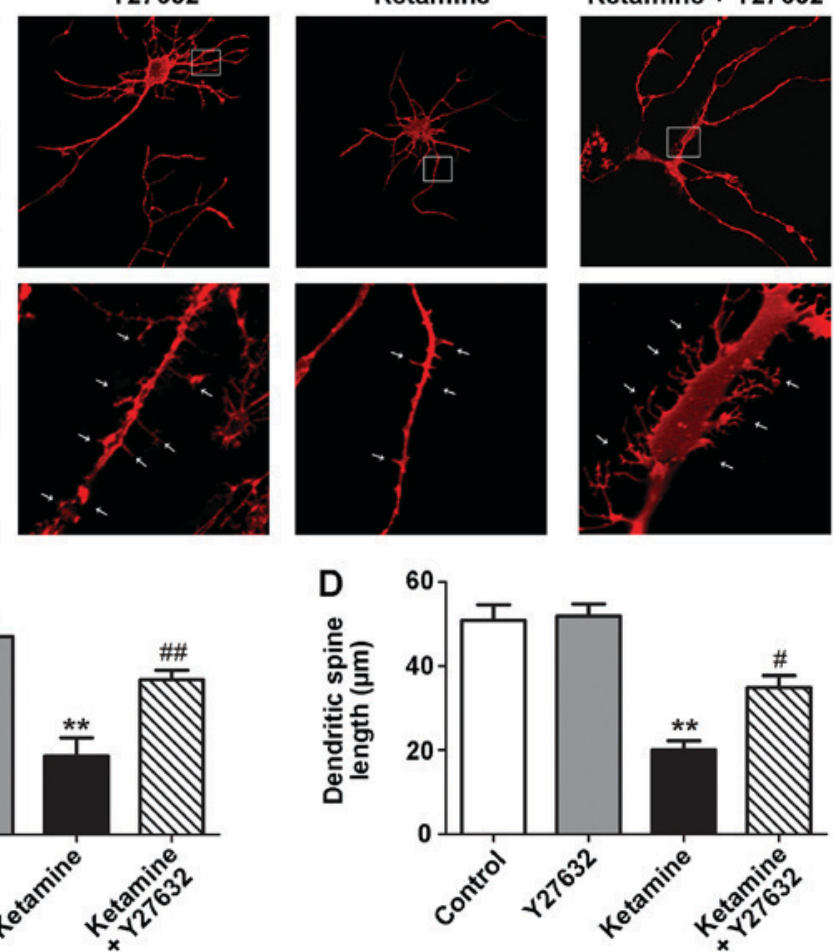

Figure 3. ROCK Y27632 prevents ketamine-induced dendritic spine loss and shortening in 5 DIV hippocampal neurons. The 5 DIV rat hippocampal neurons were exposed to Y27632 $(10 \mu \mathrm{M})$, ketamine $(300 \mu \mathrm{M})$ or ketamine $(300 \mu \mathrm{M})$ and Y27632 (10 $\mu \mathrm{M})$ for $6 \mathrm{~h}$. (A) Ketamine (300 $\mu \mathrm{M})$ induced upregulation of RhoA and ROCK compared with the control group. ROCK protein expression levels were attenuated by co-incubating ketamine-exposed neurons with Y27632. (B) Representative dendritic arbor development and spine images of neurons treated with control, Y27632, ketamine or ketamine plus Y27632. White arrows indicate dendritic spines. (C) Number of dendritic spines per $100 \mu \mathrm{m}$. (D) Dendritic spine length. $\mathrm{n}=10$. Magnification, $\mathrm{x} 400$ and $\mathrm{x} 1,000$. ${ }^{* *} \mathrm{P}<0.01$, ${ }^{* * *} \mathrm{P}<0.001$ vs. control; ${ }^{\#} \mathrm{P}<0.05,{ }^{\# \#} \mathrm{P}<0.01$ vs. ketamine. RhoA, transforming protein RhoA; ROCK, Rho-associated kinase; DIV, days in vitro.

demonstrated that exposure of 16-17 DIV neurons to $10 \mu \mathrm{M}$ Y27632 altered the morphology of dendritic spines. In the present study, an increase in number and length of dendritic spines was not observed following treatment of 5 DIV neurons with $10 \mu \mathrm{M}$ Y27632 for $6 \mathrm{~h}$, which may be due to the relatively fewer developing neurons or the low concentration of Y27632. Y27632 in the presence of ketamine attenuated the dendritic spine loss and length-shortening induced by ketamine. Therefore, it was hypothesized that in addition to the RhoA/ROCK signaling pathway, there are other molecular mechanisms involved in the synaptic structural plasticity induced by ketamine.

Previous studies demonstrated that there are a number of possible mechanisms by which ketamine induces neurotoxicity in the developing brain, including suppression of phosphorylated (p)-protein kinase $\mathrm{C} \gamma$ and $\mathrm{p}$-extracellular signal-regulated kinase (34), upregulation of neuronal microRNA 124 (35), inhibition of the frequency and amplitude of calcium oscillations (36), decrease in glycogen synthase kinase- $3 \beta$ phosphorylation (37), and activation of the phosphoinositide 3-kinase/protein kinase B signaling pathways. However, there are fewer studies focused on the effect of ketamine on hippocampal dendritic spines. The present study has identified another mechanism whereby ketamine affects the plasticity of hippocampal dendritic spines and may contribute to neurotoxicity in the developing brain.

The present study has a number of limitations. Exposure to anesthetics transiently affects the dynamics of dendritic spines, and dendritic protrusion loss and shrinkage are reversible $(17,31,38)$. The present study was based on single time-point observations; it is not known whether ketamine-induced effects on the morphology and number of dendritic spines may be attenuated upon ketamine elimination. Repeated exposure to ketamine during early development impairs motor learning and learning-dependent plasticity of dendritic spines later in life (13). The in vitro model used in the 
present study only demonstrated that ketamine decreases the number and length of dendritic spines. Further experiments on animals are required to investigate the possible effects of ketamine on behavior.

In summary, the present study demonstrated that exposure to ketamine during the period of rapid synaptogenesis causes loss and length-shortening of dendritic spines in cultured rat hippocampal neurons. Inhibition of ROCK by Y27632 attenuates the effects of ketamine on dendritic spines. The present novel data suggested that ketamine affects the formation of synapses partly through the RhoA/ROCK signaling pathway. Therefore, further studies on the RhoA/ROCK signaling pathways in ketamine-induced neurotoxicity in children are required.

\section{Acknowledgements}

The authors would like to thank Ms. Hanying Xing of the Hebei General Hospital (Shijiazhuang, China) for her technical assistance.

\section{Funding}

The present study was supported by the Natural Science Foundation of Hebei Province (grant no. H2014206454).

\section{Availability of data and materials}

The datasets used and/or analyzed during the current study are available from the corresponding author on reasonable request.

\section{Authors' contributions}

LH and RK conceived and designed the study. Primary neuron cultures and immunofluorescence procedures were performed by $\mathrm{ZH}, \mathrm{RZ}$ and YW. Spine densities were analyzed by XL and LB. XD and ZH performed the western blot analysis. SJ participated in the analysis and processing of experiments and data, and wrote the paper. All authors read and approved the final manuscript.

\section{Ethics approval and consent to participate}

Animal experiments were performed according to the regulations of laboratory animal management by the Ministry of Science and Technology of the People's Republic of China (1988) no. 134, which conforms to the internationally recognized National Institutes of Health (Bethesda, MD, USA) guidance for care and use of laboratory animals. The Institutional Animal Care and Use Committee of Hebei Medical University specifically approved the present study.

\section{Patient consent for publication}

Not applicable.

\section{Competing interests}

The authors declare that they have no competing interests.

\section{References}

1. Young C, Jevtovic-Todorovic V, Qin YQ, Tenkova T, Wang H, Labruyere J and Olney JW: Potential of ketamine and midazolam, individually or in combination, to induce apoptotic neurodegeneration in the infant mouse brain. Br J Pharmacol 146: 189-197, 2005.

2. Lee BH, Chan JT, Hazarika O, Vutskits L and Sall JW: Early exposure to volatile anesthetics impairs long-term associative learning and recognition memory. PLoS One 9: e105340, 2014.

3. DiMaggio C, Sun LS and Li G: Early childhood exposure to anesthesia and risk of developmental and behavioral disorders in a sibling birth cohort. Anesth Analg 113: 1143-1151, 2011.

4. Green SM, Roback MG, Kennedy RM and Krauss B: Clinical practice guideline for emergency department ketamine dissociative sedation: 2011 update. Ann Emerg Med 57: 449-461, 2011.

5. Mistry RB and Nahata MC: Ketamine for conscious sedation in pediatric emergency care. Pharmacotherapy 25: 1104-1111, 2005.

6. Paule MG, Li M, Allen RR, Liu F, Zou X, Hotchkiss C, Hanig JP, Patterson TA, Slikker W Jr and Wang C: Ketamine anesthesia during the first week of life can cause long-lasting cognitive deficits in rhesus monkeys. Neurotoxicol Teratol 33: 220-230, 2011.

7. Scallet AC, Schmued LC, Slikker W Jr, Grunberg N, Faustino PJ, Davis H, Lester D, Pine PS, Sistare F and Hanig JP: Developmental neurotoxicity of ketamine: Morphometric confirmation, exposure parameters, and multiple fluorescent labeling of apoptotic neurons. Toxicol Sci 81: 364-370, 2004.

8. Matus A: Actin-based plasticity in dendritic spines. Science 290: 754-758, 2000.

9. Rochefort NL and Konnerth A: Dendritic spines: From structure to in vivo function. EMBO Rep 13: 699-708, 2012.

10. Blanpied TA and Ehlers MD: Microanatomy of dendritic spines: Emerging principles of synaptic pathology in psychiatric and neurological disease. Biol Psychiatry 55: 1121-1127, 2004.

11. McCann RF and Ross DA: A Fragile balance: Dendritic Spines, Learning, and Memory. Biol Psychiatry 82: e11-e13, 2017.

12. Tan H, Ren RR, Xiong ZQ and Wang YW: Effects of ketamine and midazolam on morphology of dendritic spines in hippocampal CA1 region of neonatal mice. Chin Med J (Engl) 122: 455-459, 2009.

13. Huang L and Yang G: Repeated exposure to ketamine-xylazine during early development impairs motor learning-dependent dendritic spine plasticity in adulthood. Anesthesiology 122: 821-831, 2015.

14. Olson MF: Contraction reaction: Mechanical regulation of Rho GTPase. Trends Cell Biol 14: 111-114, 2004.

15. Hedrick NG and Yasuda R: Regulation of Rho GTPase proteins during spine structural plasticity for the control of local dendritic plasticity. Curr Opin Neurobiol 45: 193-201, 2017.

16. Lemkuil BP, Head BP, Pearn ML, Patel HH, Drummond JC and Patel PM: Isoflurane neurotoxicity is mediated by p75NTR-RhoA activation and actin depolymerization. Anesthesiology 114: 49-57, 2011.

17. Zimering JH, Dong Y, Fang F, Huang L, Zhang Y and Xie Z: Anesthetic sevoflurane causes Rho-dependent filopodial shortening in mouse neurons. PLoS One 11: e0159637, 2016.

18. Nagy D, Kocsis K, Fuzik J, Marosi M, Kis Z, Teichberg VI, Toldi J and Farkas T: Kainate postconditioning restores LTP in ischemic hippocampal CA1: Onset-dependent second pathophysiological stress. Neuropharmacology 61: 1026-1032, 2011.

19. Caceres A, Banker G, Steward O, Binder L and Payne M: MAP2 is localized to the dendrites of hippocampal neurons which develop in culture. Brain Res 315: 314-318, 1984.

20. Castaneda P, Munoz M, Garcia-Rojo G, Ulloa JL, Bravo JA, Márquez R, García-Pérez MA, Arancibia D, Araneda K, Rojas PS, et al: Association of N-cadherin levels and downstream effectors of Rho GTPases with dendritic spine loss induced by chronic stress in rat hippocampal neurons. J Neurosci Res 93: 1476-1491, 2015.

21. Swanger SA, Mattheyses AL, Gentry EG and Herskowitz JH: ROCK1 and ROCK2 inhibition alters dendritic spine morphology in hippocampal neurons. Cell Logist 5: e1133266, 2016.

22. Cohen ML, Chan SL, Way WL and Trevor AJ: Distribution in the brain and metabolism of ketamine in the rat after intravenous administration. Anesthesiology 39: 370-376, 1973.

23. Giardina SF, Cheung NS, Reid MT and BeartPM: Kainate-induced apoptosis in cultured murine cerebellar granule cells elevates expression of the cell cycle gene cyclin D1. J Neurochem 71: 1325-1328, 1998. 
24. Soriano SG, Liu Q, Li J, Liu JR, Han XH, Kanter JL, Bajic D and Ibla JC: Ketamine activates cell cycle signaling and apoptosis in the neonatal rat brain. Anesthesiology 112: 1155-1163, 2010.

25. Zheng X, Zhou J and Xia Y: The role of TNF- $\alpha$ in regulating ketamine-induced hippocampal neurotoxicity. Arch Med Sci 11: 1296-1302, 2015.

26. De Roo M, Klauser P, Briner A, Nikonenko I, Mendez P, Dayer A, Kiss JZ, Muller D and Vutskits L: Anesthetics rapidly promote synaptogenesis during a critical period of brain development. PLoS One 4: e7043, 2009.

27. Elia LP, Yamamoto M, Zang K and Reichardt LF: p120 catenin regulates dendritic spine and synapse development through Rho-family GTPases and cadherins. Neuron 51: 43-56, 2006.

28. Newell-Litwa KA, Badoual M, Asmussen H, Patel H, Whitmore L and Horwitz AR: ROCK1 and 2 differentially regulate actomyosin organization to drive cell and synaptic polarity. J Cell Biol 210: 225-242, 2015.

29. Pozueta J, Lefort R, Ribe EM, Troy CM, Arancio O and Shelanski M: Caspase-2 is required for dendritic spine and behavioural alterations in J20 APP transgenic mice. Nat Commun 4: 1939, 2013.

30. Tashiro A and Yuste R: Regulation of dendritic spine motility and stability by Rac1 and Rho kinase: Evidence for two forms of spine motility. Mol Cell Neurosci 26: 429-440, 2004.

31. Platholi J, Herold KF, Hemmings HC Jr and Halpain S: Isoflurane reversibly destabilizes hippocampal dendritic spines by an actin-dependent mechanism. PLoS One 9: e102978, 2014.
32. Darenfed H, Dayanandan B, Zhang T, Hsieh SH, Fournier AE and Mandato CA: Molecular characterization of the effects of Y-27632. Cell Motil Cytoskeleton 64: 97-109, 2007.

33. Kang MG, Guo Y and Huganir RL: AMPA receptor and GEF-H1/Lfc complex regulates dendritic spine development through RhoA signaling cascade. Proc Natl Acad Sci USA 106: 3549-3554, 2009 .

34. Huang L, Liu Y, Jin W, Ji X and Dong Z: Ketamine potentiates hippocampal neurodegeneration and persistent learning and memory impairment through the PKCgamma-ERK signaling pathway in the developing brain. Brain Res 1476: 164-171, 2012.

35. Xu H, Zhang J, Zhou W, Feng Y, Teng S and Song X: The role of miR-124 in modulating hippocampal neurotoxicity induced by ketamine anesthesia. Int J Neurosci 125: 213-220, 2015.

36. Huang L, Liu Y, Zhang P, Kang R, Liu Y, Li X, Bo L and Dong Z: In vitro dose-dependent inhibition of the intracellular spontaneous calcium oscillations in developing hippocampal neurons by ketamine. PLoS One 8: e59804, 2013.

37. Liu JR, Baek C, Han XH, Shoureshi P and Soriano SG: Role of glycogen synthase kinase- $3 \beta$ in ketamine-induced developmental neuroapoptosis in rats. Br J Anaesth 110 (Suppl 1): i3-i9, 2013.

38. Yang G, Chang PC, Bekker A, Blanck TJ and Gan WB: Transient effects of anesthetics on dendritic spines and filopodia in the living mouse cortex. Anesthesiology 115: 718-726, 2011.

This work is licensed under a Creative Commons Attribution-NonCommercial-NoDerivatives 4.0 International (CC BY-NC-ND 4.0) License. 